\title{
Classification and description of chronic pain among HIV positive patients in Uganda
}

1. Emmanuel K Mwesiga; Makerere University, College of Health Sciences, 7072 Kampala, Uganda Email: emwesiga@chs.mak.ac.ug

2. Mark Kaddumukasa; Makerere University, College of Health Sciences, 7072 Kampala, Uganda Email: kaddumark@yahoo.co.uk

3. Levicatus Mugenyi; Infectious Disease Research Collaboration, Mulago Hill Road, MUJHU3

Building. P.O. Box 7475 Kampala, Uganda. Email: lmugenyi005@gmail.com

4. Noeline Nakasujja; Makerere University, College of Health Sciences, 7072 Kampala, Uganda.

Email:drnoeline@yahoo.com

\begin{abstract}
Introduction: Chronic pain classification in HIV positive patients is essential for diagnosis and treatment. However, this is rarely done despite association with poor outcomes.

Methods: A cross-sectional survey of 345 consented patients at a specialized HIV care center in Uganda was conducted. Chronic pain was defined as pain of more than two weeks duration. Data was collected using a socio-demographic questionnaire, the IASP classification of chronic pain; the StEP; Mini Mental Status Examination, Patient Health Questionnaire, Mini International Neuropsychiatric Interview and the World Health Organization quality of life instrument brief version. Chi-square, Fisher's exact, t-test and logistic regression analyses were carried out to determine factors associated with chronic pain.
\end{abstract}

Results: Description of pain aetiology was difficult. Chronic pain was reported in $21.5 \%$ of the participants. Non-neuropathic $(92.0 \%)$ was more common than neuropathic pain (8.0\%). Chronic pain was found to be associated with feeling ill [OR=6.57 $(3.48-12.39)]$, and worse scores in the quality of life domain for physical health [OR=0.71 $(0.60-0.83)]$.

Conclusion: People living with HIV/AIDS commonly have chronic pain that is associated with poor quality of life. More sensitive tools are needed to accurately describe chronic pain in resource limited settings.

Keywords: Chronic pain, classification, HIV/AIDS.

DOI: https://dx.doi.org/10.4314/ahs.v19i2.20

Cite as: Mwesiga EK, Kaddumukasa M, Mugenyi L, Nakasujja N. Classification and description of chronic pain among HIV positive patients in Uganda. Afri Health Sci.2019;19(2): 1978-1987. https:/ / dx.doi.org/10.4314/abs.v19i2.20

\section{Introduction}

Pain in its simplest classification may be described as either acute pain (AP) or chronic pain $(\mathrm{CP})^{1}$. AP may be nociceptive or inflammatory pain ${ }^{2,3}$ and is provoked by a specific disease or injury, serves a useful biologic purpose and is self-limited ${ }^{4}$. CP has also been described as pathological pain ${ }^{2}$ and includes dysfunctional and neuropathic

\section{Corresponding author: \\ Emmanuel K Mwesiga, \\ Department of Psychiatry, \\ College of Health Sciences; \\ Makerere University. \\ Tel: +256 782272757 \\ Email: emwesiga@chs.mak.ac.ug}

pain $^{2,3}$. It has been argued to be a disease in and of itself with clear pathology, symptom patterns and management approaches which are different to acute pain ${ }^{5}$. It is pain that outlasts the normal time of healing, if associated with a disease or injury. CP may arise from psychological states, serves no biologic purpose, and has no recognizable end-point.Different pain classifications have different mechanisms and therefore require different management strategies.

The literature on pain classification tools for the description of pain among people living with HIV/AIDS (PLWHA) is limited and inconsistent ${ }^{6-8}$. The majority of literature from sub Saharan Africa has described $\mathrm{AP}^{6,9-14}$. Literature on AP among PLWHA reveals that it is both common and burdensome $e^{6,8,13,15}$. AP has also consistently been associated with increased drug use, poor quality of

(C) 2019 Mwesiga et al. Licensee African Health Sciences. This is an Open Access article distributed under the terms of the Creative commons Attribution License (https://creativecommons.org/licenses/BY/4.0), which permits unrestricted use, distribution, and reproduction in any medium, provided the original work is properly cited. 
life (QOL) and increased morbidity and mortality ${ }^{9,16}$. Similar literature on descriptions and factors associated with CP among PLWHA from sub Saharan Africa is limited and inconsistent.

CP among PLWHA may be argued to be a syndrome due to its marked diversity to involve various regions, systems, intensities, characteristics, etiologies and a host of co morbidities like substance use and depression ${ }^{7,10,12}$. The prevalence rates and factors associated with CP may differ from those of acute pain in PLWHA as CP persists beyond normal healing time of the causative mechanism. Also, because CP is persistent it might have worse outcomes on various morbidity statistics like quality of life. Factors that have been associated with AP in PWHA like immune status and HAART regimens <="" span="" style="font-family: "Times New Roman";">The current literature on pain in PLWHA has dwelt on AP and as such not many tools areavailable to describe CP. Tools like the Neuropathic Pain Scale that are available for describing CP are limited inuse given that they are valid for only specific types of pain ${ }^{17}$. CP in PLWHA however has been found to beheterogeneous affecting various sites at different intensities and by various mechanisms ${ }^{7,13,18}$.To ensure better management of CP in PLWHA better description of $\mathrm{CP}$ is required. A clearer description of $\mathrm{CP}$ in PLWHA improvesour understanding of mechanisms that can enable one to suggest appropriate treatments. Classification and description of $\mathrm{CP}$ allows specialists to group conditions in order to better understand disease mechanisms ${ }^{1}$ and to improve on management strategies. In this report, we characterised CP using the International Association for the Study of Pain (IASP) classification of chronic pain; and the Standardised Evaluation of Pain (StEP). We also described the factors associated with CP among HIV positive patients attending a centre of excellence for HIV care in Uganda.

\section{Methods}

Study design and setting: This was a cross-sectional study done at Mildmay Uganda which is a specialised HIV care centre located at Lweza, $12 \mathrm{~km}$ from the Ugandan capital. It was officially opened in 1998 as a Centre of Excellence for provision of comprehensive HIV \& AIDS prevention, care, treatment and training service. As one of the oldest HIVcare centres in the country, it reviews over 200 patients a day on an out-patient basis at Lweza. It also has satellite clinicsin 16 districts around the coun- try offering specialised HIV care. At the centre, it runs daily offering general care to patients but also has specialist clinics on specific days in the week. A psychiatry clinic is run every Tuesday by aconsultant psychiatrist.

Ethical approval: Approval for the study was obtained from the Makerere University College of Health Sciences, School of Medicine Research and Ethics Committee, Mildmay Uganda Research and Ethics Committee and the Uganda National Council of Science and Technology. No individual participant data is reported.

\section{Chronic pain measures}

CP classification was done using the IASP, classification of Chronic pain ${ }^{19}$ and the Standardized Evaluation of Pain was designed by Scholz et $\mathrm{al}^{20}$. CP was described as pain of more than two weeks duration. A duration of two weeks was used to avoid documenting acute pain which is defined as "the normal, predicted physiological response to an adverse chemical, thermal or mechanical stimulus associated with surgery, trauma and acute illness ${ }^{21}$." Most tools that assess for acute pain describe it as pain of one week duration. The IASP classification on the other hand classifies acute pain as pain of less than one month ${ }^{19}$. The decision of two weeks was made to exclude acute pain but allowed for all pain durations using the IASP classification of chronic pain.

The IASP classification describes pain according to five different axes. Axis I records the region of the body affected while axis II records the system involved. Temporal characteristics of pain and pattern of occurrence are recorded on axis III. Axis IV records the patient's statement of intensity and time since onset of pain with aetiology of the pain recorded on axis $\mathrm{V}$. Total scores were then added to generate a five digit code that is correlated to a specific diagnosis of known pathophysiology. Scores of axis IV are not considered in generating diagnostic codes due to the variability of patient's perception of pain intensities and also to account for recall bias in noting the correct duration of pain ${ }^{22}$. Patient codes that were exactly similar to codes in the manual were matched to known diagnoses in the classification manual and reported. Not all codes in the IASP classification have been awarded corresponding codes for diagnoses of known pathophysiology at this time and as such some pains might be unclassified for now. Generated codes that could not be matched to any 
code in the manual were reported as 'unallocated codes.' If codes differed only in the etiological mechanisms but had similar classifications of region system and temporal characteristics, 'differing etiology' was reported after confirming that the code would have been generated was an unallocated code in the IASP classification.

The Standardized Evaluation of Pain was designed by Scholz et al ${ }^{20}$ It is used to differentiate neuropathic from non neuropathic pain and has been validated in patients with chronic back pain. It has been found to have better sensitivity and specificity than the $\mathrm{DN} 4^{18}$ for screening for neuropathic pain. In this study, it was used to generate scores that differentiate neuropathic from non neuropathic pain. Total scores of more than 4 from all the questions are suggestive of neuropathic pain while scores of four and below are indicative of non neuropathic pain.

Study procedure: All recruited adult patients receiving care from Mildmay Uganda centre at Lweza who consented to the study made up the sampling frame. We initially assessed for cognitive impairment using the mini mentalstatus examination (MMSE). We included patients in care above 18 years of age and excluded those MMSE scores less than or equal to 19 . We also excluded participants too ill to participate or those who needed referral for inpatient care. Using Leslie Kish formula ${ }^{23}$ we estimated asample size of three hundred and eighty one participants at a precision of $5 \%$ and anticipated prevalence of $42.8 \%$ based on a study by Miaskowski et al $2011^{24}$, depressive episode using the Patient Health Questionnaire (PHQ) ${ }^{25}$ and confirmed using the MINI International Neuropsychiatric Inventory (MINI) (26). Finally, data extraction from patients medical records was done for CD4 counts, HAART regimens and past treatment or diagnosis for pain and depression. Data was collected over a four month period between September 2013 and December 2013.
Data analysis: Data was analyzed using STATA Version 12 (StataCorp. 2011. Stata Statistical Software: Release 12. College Station, TX: StataCorp LP). Participants with CP were assigned diagnoses according to the IASP classiication and StEP. To test for associations, the dependent variable was the presence of CP. Socio-demographic factors, clinical characteristics, quality of life and depression status were the independent variables. Chi-square, Fisher's exact and t-tests were carried out to identify potential factors associated with CP. The factors with $\mathrm{p}$-value $<0.25$ were then entered into a multiple logistic regression and model building done using a likelihood ratio test. In case of correlated independent variables (multi co linearity problem) mean centering was done. This is a statistical method to deal with collinearity which involves subtracting the mean from all data points therefore shifting the scale of the variable and is usually applied to predictors ${ }^{27}$. If centering did not solve the problem, then one of the correlated variables explaining the larger variability, that is, the one with a smaller bi-variable $\mathrm{p}$ value was retained.

\section{Results}

Between September and December 2013, 373 patients were invited to participate in the study. Six participants were excluded due to severe cognitive impairment (MMSE scores <19). After cleaning of data by removal of duplicates and incomplete records, 345 records remained for analysis.

Seventy four out of the 345 participants $(21.5 \%)$ reported having CP. The majority 69/74 (93.2\%) reported pain at only one site. For participants who reported CP, the mean age was $38.6(\mathrm{SD}=9.9)$ years while mean scores for cognitive function on the MMSE were 27.6 (SD=2.9). The few patients not on HAART (15/74) were receiving daily septrin prophylaxis. The median CD4 count was 376 cells $/ \mathrm{mm}^{3}$ (IQR: 256 - 581) and 49 participants $(66.2 \%)$ reported currently feeling ill primarily with pain related complaints. There were no differences in terms of gender, marital status, level of education or age for those with chronic pain. More results are shown in table I. 
Table 1: Description of participant baseline characteristics

\begin{tabular}{|c|c|c|c|c|}
\hline \multirow[t]{2}{*}{ Variable } & \multirow{2}{*}{$\begin{array}{l}\text { All Patients } \\
\text { N (\%) }\end{array}$} & \multicolumn{2}{|c|}{ Chronic Pain } & \multirow[t]{2}{*}{ P-value } \\
\hline & & $\begin{array}{l}\text { Yes } \\
\text { N }(\%)\end{array}$ & $\begin{array}{l}\text { No } \\
\text { N (\%) }\end{array}$ & \\
\hline \multicolumn{2}{|l|}{ MMSE } & & & \multirow[t]{4}{*}{0.285} \\
\hline Moderate & $46(13.33)$ & $14(18.92)$ & $32(11.85)$ & \\
\hline Mild & $44(12.75)$ & $9(12.16)$ & $35(12.96)$ & \\
\hline Normal & $255(73.91)$ & $51(68.92)$ & $203(75.19)$ & \\
\hline \multicolumn{2}{|l|}{ Reported ill } & & & \multirow[t]{3}{*}{0.000} \\
\hline Yes & $92(26.67)$ & $49(66.22)$ & $43(15.93)$ & \\
\hline No & $253(73.33)$ & $25(33.78)$ & $227(84.07)$ & \\
\hline \multicolumn{2}{|l|}{ Immunological stage } & & & \multirow[t]{5}{*}{0.978} \\
\hline Severe $(<200$ cells/mm3) & $58(17.47)$ & $14(18.92)$ & $44(17.12)$ & \\
\hline Advanced (200-349cells/mm3) & $74(22.29)$ & $17(22.97)$ & $57(22.18)$ & \\
\hline Mild (350-499cells/mm3) & $67(20.18)$ & $14(18.92)$ & $52(20.23)$ & \\
\hline Not significant $(>500$ cells $/ \mathrm{mm} 3)$ & $133(40.06)$ & $29(39.19)$ & $104(40.47)$ & \\
\hline \multicolumn{2}{|l|}{ On HAART } & & & \multirow[t]{3}{*}{0.268} \\
\hline Yes & $287(83.92)$ & $59(79.73)$ & $228(85.07)$ & \\
\hline No & $55(16.08)$ & $15(20.27)$ & $40(14.93)$ & \\
\hline \multicolumn{2}{|l|}{ Prior Depression Diagnosis } & & & \multirow[t]{3}{*}{0.528} \\
\hline Yes & $14(4.11)$ & $4(5.41)$ & $10(3.76)$ & \\
\hline No & $326(95.82)$ & $70(94.59)$ & $256(96.24)$ & \\
\hline \multicolumn{2}{|l|}{ Prior Pain Diagnosis } & & & \multirow[t]{3}{*}{0.005} \\
\hline Yes & $19(5.57)$ & $9(12.16)$ & $10(3.76)$ & \\
\hline No & $321(94.41)$ & $65(87.84)$ & $256(96.24)$ & \\
\hline \multicolumn{2}{|l|}{ Major Depressive Episode } & & & \multirow[t]{3}{*}{0.000} \\
\hline Yes & 34 (10.97) & $17(22.97)$ & $17(6.30)$ & \\
\hline No & $310(89.03)$ & $57(77.03)$ & $253(93.70)$ & \\
\hline \multicolumn{2}{|l|}{ HAART Regimen } & & & \multirow[t]{5}{*}{0.798} \\
\hline None & $56(16.23)$ & $15(20.27)$ & $41(15.19)$ & \\
\hline AZT based regimen & $134(38.84)$ & $24(32.43)$ & $109(40.37)$ & \\
\hline TDF based regimen & $141(40.87)$ & $32(4.24)$ & $109(40.37)$ & \\
\hline Other & $14(3.65)$ & $3(4.05)$ & $11(4.07)$ & \\
\hline \multicolumn{2}{|l|}{$\begin{array}{l}\text { Previous } \\
\text { depression treatment }\end{array}$} & & & \multirow[t]{3}{*}{0.302} \\
\hline None & $327(95.89)$ & $71(94.59)$ & $256(96.24)$ & \\
\hline Yes & $14(4.11)$ & $4(5.41)$ & $10(3.76)$ & \\
\hline \multicolumn{2}{|l|}{ Previous pain treatment } & & & \multirow[t]{3}{*}{0.033} \\
\hline \multirow{2}{*}{$\begin{array}{l}\text { None } \\
\text { Yes }\end{array}$} & $323(94.44)$ & $66(89.19)$ & $256(95.88)$ & \\
\hline & $18(5.56)$ & $8(10.81)$ & $11(4.12)$ & \\
\hline \multicolumn{5}{|l|}{ Quality of life (Mean, SD) } \\
\hline Physical Health & $15.43(2.20)$ & $13.58(2.75)$ & $15.94(1.71)$ & 0.000 \\
\hline Psychological & $16.16(2.16)$ & $15.14(2.82)$ & $16.31(1.87)$ & 0.000 \\
\hline Social relationships & $13.78(2.99)$ & $13.91(2.97)$ & $13.74(3.00)$ & 0.662 \\
\hline Environment & $14.68(1.83)$ & $13.81(2.24)$ & $14.91(1.63)$ & 0.000 \\
\hline
\end{tabular}

Among the 69 participants who reported pain at one site, the region (axis I) most affected was the lower back region 18/69 (26.1\%). For axis II (system), the musculoskeletal system was most affected with 43/69 (62.3\%). No pain was associated to more than two systems. For axis III (Temporal Characteristics of Pain: Pattern of Occurrence) $27 / 69(39.1 \%)$ reported pain that was re- curring irregularly. A total of 20/69 (29.0\%) reported pain of medium intensity of 1 to 6 months duration on axis IV (Patient's Statement of Intensity: Time since Onset of Pain). Axis V (Aetiology) was hard to determine with 41/69 (59.4\%) of the participants having their pain reported as unknown or other on axis V. Additional descriptive statistics are shown in table 2 . 
Table 2: IASP classification of chronic pain at one pain site.

\begin{tabular}{|c|c|c|c|}
\hline Characteristic & & Frequency & Percentage (\%) \\
\hline \multirow[t]{9}{*}{ Region } & $\begin{array}{l}\text { Lower back, lumbar spine, sacrum and } \\
\text { coccyx }\end{array}$ & 18 & 26.1 \\
\hline & Lower limbs & 12 & 17.4 \\
\hline & Upper shoulder and limbs & 10 & 14.5 \\
\hline & Head face and mouth & 9 & 13.0 \\
\hline & Thoracic region & 9 & 13.0 \\
\hline & Abdominal region & 7 & 10.1 \\
\hline & Cervical region & 2 & 2.9 \\
\hline & Anal, perianal and genital region & 1 & 1.4 \\
\hline & More than three sites & 1 & 1.4 \\
\hline \multirow[t]{6}{*}{ System } & $\begin{array}{l}\text { Musculoskeletal system and connective } \\
\text { tissue }\end{array}$ & 43 & 62.3 \\
\hline & Gastrointestinal system & 9 & 13.0 \\
\hline & $\begin{array}{l}\text { Nervous system (central, peripheral, and } \\
\text { autonomic) and special senses; physical } \\
\text { disturbance or dysfunction }\end{array}$ & 8 & 11.6 \\
\hline & $\begin{array}{l}\text { Cutaneous and subcutaneous and associated } \\
\text { glands (breast, apocrine, etc.) }\end{array}$ & 4 & 5.8 \\
\hline & Respiratory and cardiovascular systems & 3 & 4.4 \\
\hline & Genito-urinary system & 2 & 2.9 \\
\hline \multirow{7}{*}{$\begin{array}{l}\text { Temporal Characteristics of Pain: Pattern of } \\
\text { Occurrence }\end{array}$} & Recurring irregularly & 27 & 39.1 \\
\hline & $\begin{array}{l}\text { Continuous or nearly continuous, } \\
\text { fluctuating severity }\end{array}$ & 13 & 18.8 \\
\hline & Other combinations & 11 & 15.9 \\
\hline & Recurring regularly & 9 & 13.0 \\
\hline & $\begin{array}{l}\text { Continuous or nearly continuous, } \\
\text { nonfluctuating }\end{array}$ & 6 & 8.7 \\
\hline & None of the above & 2 & 2.9 \\
\hline & Paroxysmal & 1 & 1.4 \\
\hline \multirow{8}{*}{$\begin{array}{l}\text { Patient's Statement of Intensity: Time Since } \\
\text { Onset of Pain }\end{array}$} & Medium-1 month to 6 months & 20 & 29.0 \\
\hline & Medium -more than 6 months & 15 & 21.7 \\
\hline & Severe- more than 6 months & 11 & 15.9 \\
\hline & Mild -I month or less & 9 & 13.0 \\
\hline & Severe- 1 month to 6 months & 7 & 10.1 \\
\hline & Severe- 1 month orless & 4 & 5.8 \\
\hline & Not recorded, not applicable, or not known & 2 & 2.9 \\
\hline & Medium - 1 month or less & 1 & 1.4 \\
\hline \multirow[t]{8}{*}{ Aetiology } & Unknown or other & 41 & 59.4 \\
\hline & Inflammatory, immune reactions & 8 & 11.6 \\
\hline & Infective, parasitic & 5 & 7.2 \\
\hline & Degenerative, mechanical & 5 & 7.2 \\
\hline & $\begin{array}{l}\text { Toxic, metabolic (e.g., alcoholic } \\
\text { neuropathy, anoxia, vascular, nutritional, } \\
\text { endocrine), radiation }\end{array}$ & 4 & 5.8 \\
\hline & Neoplasm & 3 & 4.4 \\
\hline & $\begin{array}{l}\text { Psychological origin (e.g., conversion } \\
\text { hysteria, depressive hallucination) }\end{array}$ & 2 & 2.9 \\
\hline & $\begin{array}{l}\text { Dysfunctional (including } \\
\text { psychophysiological) }\end{array}$ & 1 & 1.4 \\
\hline
\end{tabular}


Codes and associated diagnoses of known pathophysiology of all participants were reported.Only 16 (28.1\%) participants could have their chronic pain adequately classified. There were 17 (29.8\%) participants who had codes not in the IASP manual and were assigned "code unallocated." The majority of patients $24(42.1 \%)$ had codes were determining aetiology was not possible and were described as differing aetiology. No two participants had similar codes with 19/74 (25.7\%) of the participants having 'unallocated codes' and 30/74 (40.5\%) had codes with 'differing aetiology.'

Table 3 summarises the participants who had codes as per the IASP manual and their corresponding scores on StEP. ( $<4$ implies non-neuropathic pain and $>4$ implies neuropathic pain). There was more non-neuropathic (92.0\%) than neuropathic pain $(8.0 \%)$ with a mean pain score of 0.86 and a median of 0 . The inter rater reliability between the StEP scores and IASP diagnoses of participants who had pain in the lower back region (marked with an Asterix) was -0.074 .

\section{Table 3: Participants with complete IASP codes and matching StEP scores}

\begin{tabular}{|c|c|c|c|c|c|}
\hline \multicolumn{3}{|c|}{ Non Neuropathic pain $(n=11)$} & \multicolumn{3}{|c|}{ Neuropathic pain $(\mathrm{n}=5)$} \\
\hline CODE & DIAGNOSIS & $\begin{array}{l}\text { Scores on } \\
\text { StEP }\end{array}$ & CODE & DIAGNOSIS & Scores on StEP \\
\hline 533.36 & $\begin{array}{l}\text { Ankolysing } \\
\text { Spondylitis** }\end{array}$ & -2 & 632.35 & $\begin{array}{c}\text { Osteoporosis/Paget's } \\
\text { disease/Hyperparathyroi } \\
\text { dism }\end{array}$ & 5 \\
\hline 233.37 & $\begin{array}{c}\text { Pain of Psychological } \\
\text { Origin in the Shoulder } \\
\text { /Arm }\end{array}$ & -2 & 338.26 & $\begin{array}{c}\text { Thoracic } \\
\text { Spinal/Radicular Pain } \\
\text { Attributable to arthritis }\end{array}$ & 6 \\
\hline 854.08 & $\begin{array}{l}\text { Intermittent chronic anal } \\
\text { pain }\end{array}$ & 0 & 632.68 & Ankolysing Spondylitis & 10 \\
\hline $4 . \mathrm{X} 8$ & Occipital neuralgia & 0 & 532.68 & $\begin{array}{l}\text { Ankolysing } \\
\text { Spondylitis** }\end{array}$ & 12 \\
\hline 4.X8 & Occipital neuralgia & 0 & 533.68 & $\begin{array}{l}\text { Coccyx Pain } \\
\text { Syndrome** }\end{array}$ & 14 \\
\hline 4.X8 & Occipital neuralgia & 0 & & & \\
\hline 534.28 & $\begin{array}{l}\text { Coccyx Pain } \\
\text { Syndrome** }\end{array}$ & 1 & & & \\
\hline 532.58 & Osteoarthritis $* *$ & 1 & & & \\
\hline 634.38 & Night cramps & 2 & & & \\
\hline 634.28 & Night cramps & 2 & & & \\
\hline 634.08 & Night cramps & 2 & & & \\
\hline
\end{tabular}

Only 9 of the 74 participants $(12.2 \%)$ who reported CP had been previously diagnosed for their pain and all but one had some form of pain treatment. Non steroidal anti-inflammatory drugs (NSAIDS) were the primary form of pain treatment with 6 of the 8 participants who had had previous pain management having been managed with this drug class.

Significant associated factors in the unadjusted logistic regression model included reporting feeling ill $[\mathrm{OR}=10.4$ $(5.8-18.6)]$, a past pain diagnosis $[\mathrm{OR}=3.6(1.4-9.1)]$, current depressive episode $[\mathrm{OR}=0.2(0.1-0.5)]$, previous pain treatment $[\mathrm{OR}=2.8(1.1-7.3)]$ and worse scores in quality of life domains in physical health $[\mathrm{OR}=0.6(0.5$ $-0.7)$ ], psychological [OR: $0.8(0.7-0.9)$ ] and environment $[\mathrm{OR}=0.7(0.6-0.8)]$.

In the adjusted model, feeling ill at review $[\mathrm{OR}=6.57$ $(3.48-12.39)]$ as well as poor scores in the physical domain on the WHOQOL-BREF [OR=0.71 (0.60- 0.83)] were found to be associated with CP. Other results from bi-variable analyses and logistic regression are reported in Tables 1 and 4, respectively. 


\section{Table 4: Logistic regression analysis for factors associated with chronic pain}

\begin{tabular}{|c|c|c|c|c|}
\hline & \multicolumn{2}{|c|}{ Unadjusted } & Adjusted & \\
\hline Parameters & OR (95\% C.I) & $\mathbf{P}$ & OR (95\% C.I) & $\mathbf{P}$ \\
\hline Reported feeling Ill & $10.39(5.81-18.59)$ & 0.000 & $6.57(3.48-12.39)$ & 0.000 \\
\hline Depressive Episode & $0.23(0.11-0.47)$ & 0.000 & $1.17(0.41-3.34)$ & 0.769 \\
\hline Past Pain Diagnosis & $3.56(1.39-9.12)$ & 0.008 & $1.63(0.48-5.59)$ & 0.433 \\
\hline Physical health & $0.63(0.55-0.71)$ & 0.000 & $0.71(0.60-0.83)$ & 0.000 \\
\hline
\end{tabular}

\section{Discussion}

This is the first study to explore the utility of chronic pain classification among PLWHA in Uganda. The results presented above show that there was a lower prevalence of chronic pain than has been documented in most other studies ${ }^{15}$. The prevalence of CP was $21.5 \%$ which is less than other studies that have documented pain in our setting ${ }^{7,10,13}$. These studies looked at acute pain rather than chronic pain of two weeks duration and this might explain the discrepancy in figures. Unlike other studies ${ }^{13}$, pain was found more in the region of the lower back than in the lower limbs. The musculoskeletal system was most cited as being involved and this is similar to other studies done in our setting. The majority of patients reported pain of medium intensity which is similar to studies done elsewhere ${ }^{7}$ but different from a review by Parker et al who found moderate to severe intensity ${ }^{15}$. No pain was associated with more than two systems. This could have been due to difficulties among the study subjects to properly delineate which other systems/sites are involved. The duration of most pain lasting 1 to 6 months duration highlights the necessity of not fixing a specified period for chronic pain in its definition. There is need for further studies to clearly differentiate between acute and chronic pain syndromes in HIV.

The study revealed the limitations in using the IASP classification of chronic pain and the StEP for classification and description of CP. Many studies ${ }^{6,28}$ have shown that pain in PLWHA is diverse with marked heterogeneity. Despite the fact that no two participants had similar diagnostic codes, the results probably reflect the tools poor suitability as classification tools rather than heterogeneity. For the majority of participants it was difficult to describe the aetiology of the chronic pain. Many participants were therefore classified as having differing aetiology. This was a key limitation of the IASP classification as it isheavily reliant on describing the aetiology. Description of aetiology requires diagnostic tests which may not be easily available in resource limited settings. The IASP classification also resulted in many participants having "code unallocated" which is critical for classification. Development of appropriate codes for resource limited settings in critical. Classification of CP is however desirable as differing pain mechanisms with different severities were noted.The ability to differentiate neuropathic from nonneuropathic pain aids classification and thus improves on management. Our study found greater proportions of patients with CP had non-neuropathic pain. This differs from other studies that have documented larger proportions of neuropathic pain in PLWHA ${ }^{29,30}$. The reason for the differences could be due to the fact that many of the participants were on HAART and thus had better immune statuses in comparison to other studies were poor immune status was associated with neuropathic pain. Of note however, is the fact that participants who had complete IASP diagnostic codes for pain in the lower back region had poor correlation with pain mechanisms when assessed with StEP. This may reflect that the pain mechanisms described are inconsistent and support an alternate theory of neuropathic pain increasing despite HAART. There is need for further assessment to determine why StEP performs poorly in this population when differentiating neuropathic from non neuropathic pain in patients with low back pain. A molecular description of CP may also be an alternative way to describe CP in PLWHA ${ }^{31}$. A key finding of this study was the under diagnosis and under treatment of pain in this population which has been 
described before ${ }^{15,32}$. In this specialised centre when pain is diagnosed it is treated. The treatment however might not have been adequate considering many participants had ongoing pain. There is therefore need to integrate chronic pain management better pain diagnostic measures and associated treatments like cognitive behavioural therapy, physical therapy into HIV/AIDS care that takes into account various factors surrounding chronic pain care like co-morbid substance and other psychiatric dis$\operatorname{orders}^{28,33}$.

Another major finding of this study was that CP in PLWHA is associated with worse quality of life in 3 of the four domains further showing that chronic pain is debilitating with increased morbidity. People without chronic pain were more likely to have good qualityof life when compared to those without chronic pain. With only $12 \%$ of people with chronic pain having received a previous pain diagnosis or treatment further highlights the under diagnosis and treatment of pain which has implications for quality of life in this population.

Chronic pain also being associated with feeling ill is important as it may lead to increased use of services. It there for highlights the need to diagnose and treat pain in PLWHA to better manage service delivery.

$\mathrm{CP}$ was not associated with a current or past major depressive but was associated with worse outcomes in the psychological domain on quality of life. Pain and depression have been shown to be highly associated but this is not the case in terms of chronic pain in PLWHA and requires further review.

Various mechanisms have been postulated for pain in PLWHA including HAART regimes especially the D drugs, opportunistic infections, direct effect of the virus on the central nervous system and immune function ${ }^{10}$. In our study chronic pain was not associated with HAART use, HAART regimens or even CD4 counts which are markers for immune function. Chronic pain in HIV might have an alternative or multiple mechanisms that ensure it remains long after whatever insult caused it.

Limitations: The cross-sectional nature of this study makes it difficult to examine causation and therefore better designed studies might be required to explore this. Failure to clearly define the aetiology in some participants might have affected the classification. Studies where ae- tiology is clearly determined to give better agreement with already existing codes in the IASP manual should be designed. More studies are required in order to better understand the associations and the impact of the factors examined above on patients outcomes.

\section{Conclusion}

$\mathrm{CP}$ has again shown to be prevalent with worse outcomes on quality of life. This study also highlights the limitations of tools like the IASP classification of chronic pain and Standardised Evaluation of Pain in diagnosis of CP in PLWHA. There is need to design tools that can classify $\mathrm{CP}$ in PLWHA in order to prevent the under-diagnosis and under-treatment.

\section{Acknowledgements}

Special thanks go to the patients who accepted to participate in this study as well as the data collection team of Eremiah Kyanjo, Wayne Muremani and Eve Namitala.

\section{Disclosures}

Role of funding: Research reported in this publication was supported by the National Institute of Neurological Disorders and Stroke of the National Institute of Health under Award number R25NS080968 through the MEPI-Neurology Linked Programme. The content is solely the responsibility of the authors and does not necessarily represent the official views of the National Institutes of Health.

\section{Conflict of interest}

The Authors Declare no Conflict of Interest.

\section{Authors' contribution}

EKM designed the study and was also involved in data collection analysis and final write up; LM was in charge of data analysis and writing up the paper; MK and NN were involved in design and final write up. All authors read and approved the final copy before submission.

\section{References}

1. Merskey H, Bogduk N. Classification of chronic pain, IASP Task Force on Taxonomy. Seattle, WA: International Association for the Study of Pain Press (Also available online at www iasp-painorg). 1994.

2. Woolf CJ. What is this thing called pain? The Journal of Clinical Investigation. 2010;120(11):3742-4.

3. Allegri M, Clark M, De Andrés J, Jensen T. Acute and 
chronic pain: where we are and where we have to go. Minerva Anestesiol. 2012;78(2):222-35.

4. Grichnik KP, Ferrante FM. The difference Between Acute and Chronic Pain. (0027-2507 (Print)).

5. Siddall PJ, Cousins MJ. Persistent pain as a disease entity: Implications for Clinical Management. (0003-2999 (Print)). 6. Miaskowski C, Penko JM, Guzman D, Mattson JE, Bangsberg DR, Kushel MB. Occurrence and characteristics of chronic pain in a community-based cohort of indigent adults living with HIV infection. The Journal of Pain. 2011;12(9):1004-16.

7. Namisango E, Harding R, Atuhaire L, Ddungu H, Katabira E, Muwanika FR, et al. Pain among ambulatory HIV/AIDS patients: multicenter study of prevalence, intensity, associated factors, and effect. The Journal of Pain. 2012;13(7):704-13.

8. Wakeham K, Harding R, Bamukama-Namakoola D, Levin J, Kissa J, Parkes-Ratanshi R, et al. Symptom burden in HIV-infected adults at time of HIV diagnosis in rural Uganda. Journal of Palliative Medicine. 2010;13(4):37580.

9. C. Mast T, Kigozi G, Wabwire-Mangen F, Black R, Sewankambo N, Serwadda D, et al. Measuring quality of life among HIV-infected women using a culturally adapted questionnaire in Rakai district, Uganda. AIDS Care. 2004;16(1):81-94.

10. Hewitt DJ, McDonald M, Portenoy RK, Rosenfeld B, Passik S, Breitbart W. Pain Syndromes and Etiologies in Ambulatory AIDS Patients. Pain. 1997;70(2):117-23.

11. Aouizerat BE, Miaskowski CA, Gay C, Portillo CJ, Coggins T, Davis $\mathrm{H}$, et al. Risk factors and symptoms associated with pain in HIV-infected adults. Journal of the Association of Nurses in AIDS Care. 2010;21(2):125-33.

12. Del Borgo C, Izzi I, Chiarotti F, Del Forno A, Moscati AM, Cornacchione E, et al. Multidimensional aspects of pain in HIV-infected individuals. AIDS Patient Care and STDs. 2001;15(2):95-102.

13. Norval D. Symptoms and sites of pain experienced by AIDS patients: original article. South African Medical Journal. 2004;94(6):p. 450-4.

14. Rosenfeld B, Breitbart W, McDonald MV, Passik SD, Thaler H, Portenoy RK. Pain in ambulatory AIDS patients. II: Impact of pain on psychological functioning and quality of life. Pain. 1996;68(2):323-8.

15. Parker R, Stein DJ, Jelsma J. Pain in people living with
HIV/AIDS: a systematic review. Journal of the International AIDS Society. 2014;17(1).

16. Hughes J, Jelsma J, Maclean E, Darder M, Tinise X. The health-related quality of life of people living with HIV/AIDS. Disability and Rehabilitation. 2004;26(6):371-6. 17. Sandoval R, Roddey T, Giordano TP, Mitchell K, Kelley C. Pain, sleep disturbances, and functional limitations in people living with HIV/AIDS-associated distal sensory peripheral neuropathy. Journal of the International Association of Providers of AIDS Care. 2014;13(4):328-34.

18. Bouhassira D, Attal N Fau - Alchaar H, Alchaar H Fau - Boureau F, Boureau F Fau - Brochet B, Brochet B Fau - Bruxelle J, Bruxelle J Fau - Cunin G, et al. Comparison of pain syndromes associated with nervous or somatic lesions and development of a new neuropathic pain diagnostic questionnaire (DN4). (0304-3959 (Print)). 19. Melzack R. International Association for the Study of Pain. 20. Scholz J, Mannion RJ, Hord DE, Griffin RS, Rawal B, Zheng $\mathrm{H}$, et al. A novel tool for the assessment of pain: validation in low back pain. PLoS Medicine. 2009;6(4):e1000047.

21. Carr DB, Goudas LC. Acute pain. The Lancet. 1999;353(9169):2051-8.

22. Merskey H, Bogduk N. Classification of chronic pain, IASP Task Force on Taxonomy. Seattle, WA: International Association for the Study of Pain Press(Also available online at www iasp-pain org). 1994.

23. Kish L. Multipopulation survey designs: five types with seven shared aspects. International Statistical Review = Revue internationale de Statistique. 1994;62(2):167-86.

24. Skevington SM, Lotfy M, O'Connell KA. The World Health Organization's WHOQOL-BREF quality of life assessment: psychometric properties and results of the international field trial. A report from the WHOQOL group. Quality of Life Research. 2004;13(2):299-310.

25. Smarr KL, Keefer AL. Measures of depression and depressive symptoms: Beck Depression Inventory-II (BDI-II), Center for Epidemiologic Studies Depression Scale (CES-D), Geriatric Depression Scale (GDS), Hospital Anxiety and Depression Scale (HADS), and Patient Health Questionnaire-9 (PHQ-9). Arthritis Care \& Research. 2011;63(S11):S454-S66.

26. Lecrubier Y, Sheehan D, Weiller E, Amorim P, Bonora I, Harnett Sheehan K, et al. The Mini International Neuropsychiatric Interview (MINI). A short diagnostic 
structured interview: reliability and validity according to the CIDI. European Psychiatry. 1997;12(5):224-31.

27. Afshartous D, Preston RA. Key results of interaction models with centering. Journal of Statistics Education. 2011;19(3).

28. Perry BA, Westfall AO, Molony E, Tucker R, Ritchie C, Saag MS, et al. Characteristics of an ambulatory palliative care clinic for HIV-infected patients. Journal of Palliative Medicine. 2013;16(8):934-7.

29. Phillips TJ, Cherry CL, Cox S, Marshall SJ, Rice AS. Pharmacological treatment of painful HIV-associated sensory neuropathy: a systematic review and meta-analysis of randomised controlled trials. PloS one. 2010;5(12):e14433.
30. Smith HS. Treatment considerations in painful HIV-related neuropathy. Pain Physician. 2011;14(6):E50524.

31. Møller AT, Jensen TS. Pain and genes: Genetic contribution to pain variability, chronic pain and analgesic responses. European Journal of Pain Supplements. 2010;4(S4):197-201.

32. Robbins NM, Chaiklang K, Supparatpinyo K. Undertreatment of Pain in HIV+ Adults in Thailand. Journal of pain and symptom management. 2013;45(6):1061-72.

33. Merlin JS, Cen L, Praestgaard A, Turner M, Obando A, Alpert C, et al. Pain and physical and psychological symptoms in ambulatory HIV patients in the current treatment era. Journal of pain and symptom management. 2012;43(3):638-45. 